\title{
TIEMPO-ESPACIO EN LA CONSTITUCIÓN ESTATAL. UNA PERSPECTIVA DESDE LA SOCIEDAD COSTARRICENSE
}

\author{
Juan Huaylupo Alcázar*
}

RESUMEN: El autor analiza las dimensiones tiempo-espacio para estudiar la constitución histórica y social de éste, como un requisito para comprender las regresivas transformaciones del Estado, en particular del costarricense. La integración social es, para el autor, la gestación de un poder que trasciende las visiones y prácticas unilaterales, así como la asignación inédita al Estado del respeto y representación de los derechos e intereses ciudadanos. La constitución social del Estado fue la inauguración de lo público, de la política pública y de los proyectos nacionales, sin embargo, en el presente mundializado, la reforma del Estado y de la administración pública han sido los medios para autonomizar su función social, para privatizar lo público y lo nacional, así como los recursos y propiedades de la sociedad. La reconstitución social del Estado es una necesidad para revertir la supeditación de lo público al poder privado.

Palabras clave: Estado, Política pública, Administración Pública, Reforma del Estado, Privatización.

ABSTRACT: The author explores the time-space aspect to study the historical and social constitution of the State as a requirement to understand the regressive changes of it, in particular the case of Costa Rica. According to the author, social integration is the development of a power that transcends the unilateral visions and practices, as well as the unprecedented fact of a State assuming the respect and representation of citizen rights and interests. The social constitution of the State was the inauguration of the public matter, of the public politics and of the national projects; however, in the global context, the State and public administration reforms have been the means to automate its social function and to privatize what is public and national, as well as the society resources and properties. Social rebuilding of the State is necessary to revert the dependence from the private power of what is public.

KEY WORDS: State, Public politics, Public administration, State reforms, Privatization.

* Universidad de Costa Rica (jhuaylupo@costarricense.cr). 


\section{LA CONSTITUCIÓN DE LO NACIONAL: UNA CONDICIÓN}

DEL ESTADO SOCIAL

El reivindicar las relaciones espacio-tiempo-sociedad, como vínculos unitarios e integrados de los pueblos, es reconocer la interacción creativa y transformadora de los grupos humanos con su medio social, así como su relación con la naturaleza. ${ }^{1}$

La gestación de la unidad social en particulares momentos de la historia de los pueblos, a pesar de las desigualdades, ha constituido fuerzas transformadoras de sus realidades, al revolucionar la continuidad de poderes despóticos o no representativos e incluso al alterar las relaciones con quienes no comparten su proyecto social. La conformación de una comunidad de destino y la unificación de los modos de apropiarse, valorar, o dar continuidad a sus formas y contenidos culturales, ha sido trascendente en la historia de los pueblos. La constitución de lo nacional ha tenido como requisito la unificación social en la heterogeneidad societal, lo cual es más que la posesión de un territorio o el compartir una misma comunicación idiomática, ${ }^{2}$ para ser una unidad subjetiva. Asimismo, la aceptación de lo propio y común es al mismo tiempo la conciencia de lo que es ajeno o extraño.

Lo nacional o la articulación del tiempo-espacio-sociedad es un sello característico, inédito y unitario de un medio con pertenencia social. Los rasgos comunes son sólo aparentes entre las sociedades, por los distintos usos y significados sociales que se les otorga.

1 Anthony Giddens afirma: "La mayoría de los analistas sociales tratan tiempo y espacio como meros contornos de la acción y aceptan, sin advertirlo, la concepción, característica de la moderna cultura occidental, de la mensurabilidad cronológica." A. Giddens, La constitución de la sociedad, Buenos Aires, Amorrortu, 1995, p. 143.

2 Kautsky lo apreciaba directamente referido al idioma, pero también concebía lo nacional como comunidad de destino, de cultura o de carácter. Karl Kautsky, "Nacionalidad e internacionalidad", en "La segunda Internacional y el problema nacional y colonial", Cuadernos de Pasado y Presente, núm. 74, Siglo XxI, México, 1978. Stalin lo relacionaba con la convivencia cultural en un territorio determinado, el mercado y la comunidad idiomática. Maxime Rodinson Stalin, Emmanuel Terray y Rafael Ribó, El marxismo y la cuestión nacional, Barcelona, Anagrama, 1977. 
La integración e interdependencia mundial, no implica la subordinación de lo nacional a las pautas de alguna clase o nación dominante, ella supone el reconocimiento de la imposibilidad contemporánea de la autarquía, lo cual extraña compartir las capacidades y diferencias entre países. Al respecto, en abril de 1924, Otto Bauer ${ }^{3}$ afirmaba:

El capitalismo moderno ha nivelado los contenidos culturales materiales de las diferentes culturas nacionales. Pero, sin embargo, las singularidades nacionales todavía siguen teniendo efecto en el modo de apropiarse, representar, vincular, aprovechar, y continuar desarrollando esos mismos contenidos culturales materiales. La misma teoría de la relatividad penetra en la física de todas las naciones, pero en Alemania tiene que superar trabas intelectuales muy distintas que en Inglaterra; los pensadores alemanes la ponen en conexiones espirituales muy distintas y por eso la exponen de una forma distinta a como lo hacen los ingleses. La misma corriente de modo recorre la creación literaria de todos los países, pero el expresionista ruso cuenta el mismo suceso de manera distinta que el francés. El mismo movimiento obrero surge en todos los estados industriales, pero ante los mismos hechos de la explotación capitalista la clase obrera italiana reacciona de manera distinta que la escandinava. Esto es lo que tengo en mente cuando hablo de "carácter nacional". Con ello no quiero expresar aquellas imágenes mentirosas de la demagogia nacionalista, que sólo en el propio pueblo descubre héroes y mercaderes en el ajeno. ${ }^{4}$

Es tan sólo una creencia superficial suponer que lo nacional sea en todos los casos lo autóctono, o que se tenga una misma ascendencia. Muchas naciones se han nutrido de las culturas de otros pueblos, fusionándose en una sola nación. Las relaciones sociales entre los pueblos y economías no es un atributo exclusivo del capitalismo, las sociedades del pasado también se relacionaban y conformaban naciones, aun cuando no necesariamente tenían la capacidad de organizarse en estados.

La construcción de lo nacional, así como los procesos y eventos trascendentes ocurridos en espacios-tiempos determinados son irrepe-

3 Otto Bauer, La cuestión de las nacionalidades y la socialdemocracia, México, Siglo XXI, 1979 (Biblioteca del Pensamiento Socialista).

4 Ibid., p. 19. 
tibles, como también lo son las velocidades de los cambios sociales entre sociedades.

Las unidades espacio-tiempo-sociedad han creado complejas redes de interacción o nuevos nexos de comunidad en un mundo plural.

La conformación histórica de lo nacional no ha sido un destino común para todas las sociedades, las diferencias ideológicas, antagonismos de clase o las divisiones provocadas por deudas de sangre o por el dominio y manipulación de las clases políticas han atomizado a las sociedades en el espacio del poder estatal. En América Latina la integración y unidad nacional no ha sido regular ${ }^{5}$ ni su instauración adoptó formas y significados similares. De este modo, la conciencia colectiva del pasado, así como la naturaleza de la evolución de las relaciones sociales, no unificaron las relaciones en el espacio de una formación social. En esos ámbitos, la heterogeneidad social ha estado acompañada de subjetividades disímiles, contradictorias o antagónicas, que han ocasionado la imposibilidad de construir un destino común y nacional.

En algunos países de América Latina ha sido una regularidad la atomización de los mercados, la desintegración social y las manifestaciones multiculturales no convergentes en el espacio-tiempo, ${ }^{6}$ así como el establecimiento de empresas internacionales, que actúan como economías de enclave, lo cual ha limitado la articulación de las relaciones en el ámbito de una sociedad: "Un pueblo de cuatro millones de hombres, consciente de su número, no desespera nunca de su porvenir. Los mismos cuatro millones de hombres, mientras no son sino una masa inorgá-

5 "La nueva peruanidad es una cosa por crear", enunciaba Mariátegui, en 1928, pero aún tiene vigencia en ese contexto. José Carlos Mariátegui, Siete ensayos de interpretación de la realidad peruana, México, Era, 1979 (Serie Popular Era), p. 227.

${ }^{6}$ Los ámbitos de convergencia serían los límites exteriores en las relaciones sociales cotidianas establecidas de tiempos sociales o proyectos de vida compartida, lo cual implica también el establecimiento de delimitaciones espaciales. De este modo, la comunicación y movilización están restringidas a los ámbitos de convergencia, los cuales pueden ser múltiples en el espacio del poder estatal. La noción de convergencia espacio-temporal adoptada por el geógrafo Janelle, el cual es citado por Giddens, op. cit. 
nica, una muchedumbre dispersa, son incapaces de decidir su rumbo histórico." 7

La desintegración económica y la dispersión de poderes locales limitan la construcción nacional, pero también imposibilitan la creación de lo público, de lo que es común y unitario en la desigualdad social. La negación o la imposibilidad de compartir una historia y futuro común ha condicionado la polaridad ideológica y la diversidad de prácticas de actores y clases sociales. La libertad de elegir entre propietarios desiguales de recursos, capacidades e influencias, ha impuesto proyectos sociales que no son compartidos, que son excluyentes de la voluntad e interés de otros proyectos de vida de la población en un país. La desigualdad de poderes que responden a proyectos sociales distintos ha impedido la edificación de un destino social compartido.

Para fines del siglo Xx ya se había consolidado el proceso económico, en el que el país estaba incorporado al sistema capitalista internacional, debido al proceso de expansión cafetalera y a la penetración de economías de enclave, lo que había acentuado su carácter dependiente y monocultivista. También, se mantenía la naturaleza liberal-oligárquica del Estado, pues éste no intervenía para resolver los problemas de la mayoría de la población costarricense (trabajadores, peones agrícolas, artesanos y campesinos) ${ }^{8}$

Los estados en América Latina, formados tras las luchas de liberación colonial, no fueron la materialización de una nación, sino procesos continuadores del poder con distinta representación social, sin la capacidad de crear una nación. Esto es, no eran estados nacionales, fueron producto de la imposición de las fuerzas políticas triunfantes, sin proyecto ni representatividad social ni nacional. Ese Estado sólo repre-

7 En 1928, lo expresaba Mariátegui analizando y contrastando la situación de explotación de los indígenas peruanos durante los primeros periodos republicanos, frente a la precaria o nula capacidad organizativa indígena en la época, Mariátegui, op. cit., p. 45.

8 Jorge Mario Salazar, Crisis Liberal y Estado Reformista, San José, Universidad de Costa Rica, 2002 (Col. Historia de Costa Rica), p. 17. 
sentaba el poder de la fuerza de quienes habían asaltado el aparato del Estado, sean estos gamonales, militares o empresarios.

La convivencia de "comunidad" y latifundio en el Perú está, pues, perfectamente explicada, no sólo por las características del régimen del Coloniaje, sino también por la experiencia de la Europa feudal. Pero la comunidad, bajo este régimen, no podía ser verdaderamente amparada sino apenas tolerada. El latifundista le imponía la ley de su fuerza despótica sin control posible del Estado. La comunidad sobrevivía, pero dentro de un régimen de servidumbre. Antes había sido la célula misma del Estado que le aseguraba el dinamismo necesario para el bienestar de sus miembros. El coloniaje la petrificaba dentro de la gran propiedad, base de un Estado nuevo, extraño a su destino. ${ }^{9}$

El desarraigo del poder colonial implicó la formación de estados que no tenían la capacidad de representar ni crear una nación. Las fronteras de los nuevos estados fueron arbitrariamente delimitados y como auténticas "cicatrices de la historia", separaron pueblos, culturas y destinos compartidos, con la fuerza de las armas. ${ }^{10}$ Se podría afirmar que la constitución formal de algunos estados eran barreras para la unificación social en su tiempo-espacio. Así, la desintegración de la Unión Soviética posibilitó la reconformación de las naciones e incluso significó la continuación de interrumpidas disputas entre culturas y naciones en un mismo espacio de dominio estatal, como las ocurridas hace poco con las sangrientas luchas entre servios y croatas en la antigua Yugoslavia; los enfrentamientos de los chechenios en Rusia, de los vascos

9 Mariátegui, op. cit., pp. 65-66.

10 Ello no implica suponer que las naciones tengan sólo un origen cultural, por el contrario, muchas naciones son el resultado de integraciones entre las culturas con las cuales se relacionaban. Así, "[...] los italianos descienden de los etruscos, romanos, celtas, germanos, griegos y sarracenos; los franceses de los galos, romanos, britanos y germanos; los alemanes de hoy de germanos, celtas y eslavos." Bauer, op. cit., p. 23. Asimismo, la nación norteamericana no fue conformada a partir de las poblaciones aborígenes en su territorio, sino por políticos y religiosos europeos perseguidos, así como también viene siendo transformada incesantemente con inmigrantes latinoamericanos. 
en España y muchos otros en el contexto globalizado de las relaciones sociales.

Las naciones integradas en otras, pero con la convicción de un pasado y destino común, se resisten a ser absorbidas, subsumidas o reducidas a un poder estatal que no las representa ni participa de sus aspiraciones nacionales. El espacio del poder estatal se encuentra compartido, pero separado por naciones en disputa, lo cual es una barrera para la comunicación y la articulación cultural, así como para la eficacia y legitimidad del poder del Estado. En estos espacios sociales la democracia es excluyente y la paz sólo es una acumulación de fuerzas para la violencia en cualquiera de sus formas.

La unificación de los espacios sociales fragmentados en el pasado costarricense causó una profunda ruptura con los poderes locales. La posibilidad de construir un destino común e interdependiente ha sido una larga lucha contra los localismos impuestos por gamonales, caciques o caudillos en la historia latinoamericana.

La soberanía fragmentada, legada por la colonia, desapareció luego de 1821. La independencia, fruto inesperado del incendio social que devoraba a Sudamérica y México, supuso un difícil dilema: ¿cuál espacio - Cartago, Heredia, San José o Alajuela - iba ser el asiento del futuro poder central? El localismo imperante no fue fácil de vencer y estuvo en el origen de la "Batalla de Ochomogo" (1823), la conspiración de José Zamora (1826), la "Guerra de la Liga" (1835), la invasión de Quijano (1836) y las revueltas alajuelenses contra José María Castro Madriz (1847-1848). La tormenta política, sin embargo, no fue en extremo destructiva ni sangrienta $[. ..]{ }^{11}$

La unificación formal de las poblaciones y sus territorios, sin integración efectiva y sin compartir colectivamente el poder, reproducía nuevos localismos o poderes autocráticos, sin posibilidad de la gestación de una propuesta nacional.

11 Iván Molina Jiménez, Costa Rica (1800-1850), San José, Universidad de Costa Rica, 2002 (Col. Historia de Costa Rica), p. 310. 
El caudillaje militar era el producto natural de un periodo revolucionario que no había podido crear una nueva clase dirigente. El poder, dentro de esta situación, tenía que ser ejercido por los militares de la revolución que, de un lado gozaban del prestigio marcial de sus laureles de guerra y, de otro lado, estaban en grado de mantenerse en el gobierno por la fuerza de las armas. ${ }^{12}$

El Estado-nación, moderno, benefactor o social, como se le ha denominado para enfatizar algunas de sus características, no podía existir sin haber efectuado la articulación intercultural o creado los nexos de interdependencia, así como haber legalizado y legitimado el respeto a la diversidad social. El Estado que sólo representa a su clase política o exclusivamente a grupos privilegiados de la economía y de la sociedad es un Estado atrasado al servicio de intereses privados que actúan como castas sociales. La supeditación social del Estado moderno contrasta con la dominación social de caudillos, tiranos o de gobernantes electos de estados atrasados.

La conformación de lo nacional ha requerido la constitución de su Estado, que otorgue continuidad y representatividad al espíritu y tendencia colectiva. La constitución nacional ha sido una extraordinaria fuerza social, que permitió la creación de las bases políticas, ideológicas y culturales que fortalecieron y expandieron las relaciones y los procesos de valorización del capital y la integración de los mercados locales, así como la consolidación de la división del trabajo y de la producción en el espacio del poder del Estado. De este modo, las relaciones económicas obtienen el sustento social que le otorga viabilidad y continuidad a un ciclo productivo articulado nacionalmente, pero también dicha articulación propició, en algunos contextos sociales, proyectos chovinistas, reaccionarios y expansionistas, que provocaron invasiones y matanzas de exterminio racial y cultural.

En ese sentido el establecimiento de lo público no se atribuye a la gestión estatal, sino a la constitución unitaria del tiempo social en el

12 Mariátegui, op. cit., pp. 69-70. 
ámbito espacial de una nación o de un país. La determinación social de contar con un Estado no es sólo para el momento de su formación, en todo su quehacer deben estar presentes los requerimientos de la sociedad. Las tendencias, necesidades y sueños de la sociedad son las tareas y responsabilidades del Estado.

De este modo, el Estado obtiene legitimidad y con ello continuidad o estabilidad política, así como efectividad sobre la sociedad. El poder de hecho de las sociedades atrasadas se transforma en un poder de derecho en el Estado social, que norma su intervención sobre la sociedad, así como su propia actuación. El Estado social es legal y legítimo porque tiene la facultad, conferida socialmente, de dirigir o comandar a la sociedad, ${ }^{13}$ asimismo, posee la capacidad de exigir obediencia, mientras no transgreda la voluntad y aspiraciones colectivas gestadas en el tiempoespacio nacional. ${ }^{14}$

De este modo la constitución de los derechos humanos y ciudadanos, no son especulaciones ni postulaciones sin espacio ni tiempo, por el contrario, son producto de la materialización de las relaciones comunes, en un mundo donde los pueblos han conquistado formalmente derechos igualitarios sobre la desigualdad real existente. El respeto de los derechos ciudadanos es una garantía para la convivencia y la paz entre clases y para la legitimidad del Estado.

El Estado social en su devenir cotidiano armoniza la heterogeneidad social y hace suyo el interés general, también ampara y defiende lo público que se encuentra delimitado socialmente en el espacio-tiempo. La legitimidad que se alcanza es también el derecho a definir el desarrollo y devenir de lo público, lo cual se materializa a través de la mediación de la política pública y la administración institucional.

13 Norberto Bobbio, "El Poder y el Derecho", en Norberto Bobbio y Michelangelo Bovero, Origen y fundamentos del poder político, México, Grijalbo, 1985.

${ }^{14}$ La ruptura del vínculo Estado-sociedad hace ilegítimo e inestable el poder estatal, el cual pierde eficacia de regulación sobre la sociedad y pone de manifiesto la terminación de un proyecto unitario, ante la diferenciación de poderes en la sociedad que toman o intentan tomar por asalto la legalidad del aparato estatal. 


\section{EL ESTADO SOCIAL Y LA POLÍTICA PÚBLICA}

El Estado social se nutre de la desigualdad material de la sociedad capitalista y de la capacidad organizativa de los actores sociales heterogéneos. A través de ese Estado, se materializa el equilibrio de las fuerzas políticas y se configura una sociedad política ambivalente que conserva por un lado, la desigualdad social y económica con igualdad jurídica y por otro, crea las condiciones para que los excluidos cuenten con la garantía estatal para su reproducción social.

La capacidad organizativa de los actores sociales heterogéneos crearon las organizaciones del capital y del trabajo en un contexto de igualdad formal y de legalidad, garantizada por el Estado social. Los distintos protagonistas sociales requerían del Estado para amparar su actuación interesada y privada. La igualdad de derechos y relativa organización entre actores desiguales, en parte contribuyó a formar un Estado mediador y mediatizador de las clases en la sociedad. La necesidad de la función reguladora ante la desigualdad y el antagonismo fue la fuente que otorgó legitimidad y poder al Estado.

La constitución de una nueva forma política en las relaciones económicas capitalistas fue una conquista social para los sectores subalternos, pero no para crear un poder ajeno o extraño a la reproducción de las relaciones capitalistas, por el contrario, ese Estado gestó las condiciones para el crecimiento y consolidación del mercado interno, así como para la expansión del capital en todas sus formas, al permitir la liberación política y social que obstaculizaban la valorización del capital. En este proceso, los espacios provinciales y cantorales se abrieron para integrarse a la lógica de acumulación y reproducción del capital, ${ }^{15}$ que luego ampliaría sus mercados a espacios mayores.

En el aspecto económico se dio la intervención del Estado, con el objetivo de modernizar la estructura agroexportadora del capitalismo costarricen-

15 José Vega, La formación del Estado nacional en Costa Rica, San José, Instituto Centroamericano de Administración Pública, 1981. 
se. Para alcanzar este objetivo se nacionalizó la banca y se aplicó un impuesto al capital. También se impulsó el desarrollo agrícola, se estimuló la industria, se reorganizaron los ministerios de Economía y de Agricultura e Industria, se nacionalizaron los recursos hidroeléctricos del país (creación del Instituto Costarricense de Electricidad), y se reorganizó el Consejo Nacional de Producción, el cual pasó a ser una institución autónoma. ${ }^{16}$

El Estado social no ha sido la creación de un partido político ni de un caudillo, ${ }^{17}$ así como tampoco un producto de las relaciones económicas capitalistas o de una clase social, ${ }^{18}$ como individualmente se interpreta la historia en el sistema educativo costarricense. ${ }^{19}$ En el Estado social se dio la condensación de las relaciones y la actuación de todas las clases. La constitución definitiva del Estado social en Costa Rica requirió de una guerra civil para consolidar una relación unitaria que se

16 Jorge Mario Salazar, Crisis liberal y Estado reformista. Análisis político-electoral 1914-1949, San José, Universidad de Costa Rica, 2002 (Col. Historia de Costa Rica), p. 272.

17 En los procesos electorales contemporáneos, los partidos mayoritarios Liberación Nacional y Unidad Social Cristiano, se arrogan ser los creadores de una Costa Rica moderna y los gestores del bienestar de la sociedad y atacan como causantes de la crisis social y económica, aun cuando están aliados en la Asamblea Legislativa, comparten el poder político estatal y los proyectos antipopulares que degradan la calidad de vida y el desarrollo nacional.

18 Son abundantes los trabajos en la historia escrita costarricense que atribuyen la creación de un Estado social al incremento de las relaciones económicas y al haber iniciado tempranamente relaciones comerciales con el exterior, así como atribuir el crecimiento y la articulación económica a una clase empresarial. Visiones que ignoran el papel desempeñado por las clases subalternas y la función desempeñada por el Estado. Luis Paulino Vargas, Modelo desarrollista y de industrialización sustitutiva, San José, Universidad de Costa Rica, 2003 (Serie Cuadernos de Historia de las Instituciones de Costa Rica); Eduardo Oconitrillo, Un siglo de politica costarricense, San José, Universidad Estatal a Distancia, 1981; Eugenio Rodríguez, De Calderón a Figueres, San José, Universidad Estatal a Distancia, 1980; José Vega, Hacia una interpretación del desarrollo costarricense, San José, Porvenir, 1980; Óscar Aguilar, Costa Rica y sus hechos políticos de 1948, San José, Costa Rica, 1978, entre otros.

19 David Díaz Arias, Reforma sin alianza, discursos transformados, interés electoral, triunfos dudosos. La nueva interpretación histórica de la década de 1940, San José, Universidad de Costa Rica, 2003 (Serie Cuadernos de Historia de las Instituciones de Costa Rica). 
fue estructurando desde finales del siglo XIX, momento en que se creaba una nueva integración, donde todas las clases estuvieron involucradas desigualmente en un único proceso.

En Costa Rica, en la década de los años cuarenta, cuando se permitió el libre acceso de la población negra del puerto Limón al Valle Central, se legislaba garantizando los derechos de los trabajadores en el Código de Trabajo, asimismo se brindaba garantías sociales en salud, vivienda popular, lo cual era el reconocimiento de los derechos igualitarios de los habitantes. Aun cuando, terminada la Guerra Civil de 1948, las acciones de la Junta de Gobierno estuvieron fundamentalmente orientadas a dinamizar y modernizar la economía y promover la actividad agroexportadora y el comercio importador, en lo político se ilegalizaba el Partido Comunista, se cerraban sindicatos y se limitaba la actividad de la Central de Trabajadores de Costa Rica. Sin embargo, también

[...] se institucionalizó la legislación social emitida entre 1941 y 1946, se incorporó el principio de la regulación pública sobre la propiedad privada y la empresa particular, y se estipuló el derecho del Estado a dirigir y estimular la producción para lograr una mejor distribución de la riqueza. También, se proscribió el ejército (fue sustituido por una Fuerza Pública), se dieron plenos derechos políticos a la mujer, al permitírsele el derecho al sufragio y se dio garantías de la pureza electoral, al crearse el Tribunal Supremo de Elecciones (TSE) como institución autónoma del Estado, para organizar y fiscalizar las votaciones nacionales. ${ }^{20}$

Las aspiraciones y las luchas sociales en Costa Rica se materializaron de modo estatal, por lo que todos los segmentos y actores sociales estuvieron representados e integrados desigualmente. De esta manera el Estado se arrogaba el quehacer social, económico y nacional en el espacio-tiempo de su poder social, pero sin la participación directa de sus propios protagonistas.

La visión totalizante en el espacio del poder estatal se diferenciaba de las prácticas desarticuladas y directamente referidas al ámbito de los

20 Salazar, op. cit., p. 274. 
intereses personales o de clase de los estados atrasados. El Estado social respondió al surgimiento de fuerzas sociales, políticas y económicas que contribuyeron a la descomposición de la vieja sociedad, cuyos patrones de funcionamiento ya no cabían en el nuevo orden constituido.

El Estado social inauguró una nueva forma de hacer política con su capacidad de mediación y de mediatización social. Ningún segmento de la sociedad articulada fue indiferente para ese Estado, así como ningún protagonista colectivo ignoró la importancia del Estado para el logro de sus intereses. El Estado social estuvo presente en la cotidianidad de todas las relaciones sociales en el espacio-tiempo de su poder.

Esta peculiaridad social con respecto de anteriores formas estatales es la objetivación política del tiempo social, lo cual implicó la transformación del Estado, que ya no era expresión del caciquismo, gamonalismo o del poder de los propietarios que imponían la ley de su fuerza despótica sobre las colectividades locales.

El poder del Estado social era de una naturaleza que no podía reducirse a las influencias de alguna clase en particular, representaba igualitariamente la desigualdad social existente en la sociedad. El Estado amparaba la igualdad jurídica en la heterogeneidad social, marcaba con ello el límite y posibilidad de su compromiso y práctica, como se manifestaba en las garantías que brindaba para el desarrollo de la democracia representativa, la política pública, la gestión y quehacer burocrático.

El rasgo constitutivo y diferencial de la libertad moderna es su carácter jurídico [...] se trata de una libertad positiva, eminentemente mundana y laica. Desde este punto de vista, la libertad moderna es profundamente diferente de otras formas históricas de libertad. ${ }^{21}$

Este es el contexto político y social en el que surge inéditamente la posibilidad de la acción pública estatal. La igualdad, la libertad y la fraternidad inauguradas en el mundo con la Revolución francesa y americana han tenido una construcción peculiar en cada tiempo social de su

${ }^{21}$ Umberto Cerroni, La libertad de los modernos, México, Martínez Roca, 1972, p. 11. 
espacio. La formalidad igualitaria, libertaria, solidaria y fraterna de estas gestas históricas no tuvo un efecto inmediato ni automático en aquellas naciones, como tampoco podía tenerlo en otros contextos, aun cuando se plasmaba formalmente, luego de las luchas independentistas, en las Constituciones de las repúblicas latinoamericanas.

El Estado social, con relativa capacidad para redefinir la sociedad, la economía y su propia estructuración y práctica establecía el margen de su actuación, el cual estaba en relación directa con la condición, problemática y tendencias sociales en su espacio-tiempo. La conservación de la sociedad y la determinación social del quehacer estatal es, también, una necesidad para la legitimidad y continuidad del Estado social. La política pública se inauguraba como una determinación social de la práctica estatal y se revelaba como la fuente de la legitimidad social del poder estatal.

La política pública tiene una determinación dependiente de la comunidad forjada históricamente, por ello la invocación al desarrollo nacional, a la política económica o social es sustantiva en la forma y contenido del Estado social. ${ }^{22}$

La intervención pública del Estado sobre lo público es la encarnación de los intereses generales de la sociedad, y en tal sentido con posibilidad para hacer una acción prospectiva y reguladora de las tendencias y necesidades colectivas y nacionales.

Los límites de la política y la administración pública eran los del Estado social: una capacidad de acción con un poder legítimo de intervención, pero sin transgredir el orden imperante. ${ }^{23}$ La determinación de qué hacer, dónde, cuándo hacerlo y qué recursos emplear han sido una prerrogativa del Estado social en razón de su poder y representación

22 Toda política pública es una intervención del Estado, sin embargo, no es posible asociar cualquier intervención del Estado como política pública. Todo Estado de épocas anteriores a la organización capitalista han intervenido sobre la sociedad amparando los intereses de los gobernantes y de los propietarios. Un ejemplo de ello, lo constituye la imposición de tributos en el régimen feudal y esclavista.

23 Lo que Poulantzas denominó como autonomía relativa del Estado. Nicos Poulantzas, Poder político y clases sociales en el Estado capitalista, México, Siglo XXI, 1972. 
social, lo cual de ningún modo ha mostrado la autonomización absoluta de su sociedad. La capacidad de intervención de ese Estado es relativa y dependiente de las condiciones y necesidades y aspiraciones de los distintos actores sociales. La política pública no ha sido una facultad perteneciente al Estado social, sino de la sociedad que le ha impuesto condiciones para su actuación social.

En Costa Rica se evidenciaba una nueva condición cuando en el análisis del discurso inaugural del gobierno de Calderón Guardia, Víctor Hugo Acuña expresa:

[...] por un lado se manifestó respetuoso de la iniciativa privada y preocupado por la nivelación del presupuesto y, por otro lado, se declaró interesado en una mayor equidad tributaria, en el combate de la especulación y el acaparamiento y en la regulación de las relaciones entre los agentes de la producción de la caña de azúcar. En suma, fue una declaración ecléctica de intenciones, una mixtura de cristianismo social, viejo liberalismo y nuevo intervencionismo estatal. ${ }^{24}$

Estas manifestaciones del gobierno de aquel tiempo expresaban que sus acciones interventoras no serían arbitrarias ni espontáneas, sino producto de una lectura de la sociedad y la adopción de una posición de compromiso con la reproducción del sistema imperante. De este modo, la planificación, las políticas públicas y las políticas sectoriales eran resultado del conocimiento de la realidad, así como de los propósitos e intencionalidades de sus acciones para la sociedad en su conjunto y para los distintos sectores sociales en particular. El diseño y ejecución de las políticas y de los planes de desarrollo eran un requisito para la manifestación del Estado en una sociedad totalizante.

Asimismo, la intervención estatal en una sociedad articulada e interdependiente establecía una condición a la función pública del Estado, así como a los procesos de concertación y negociación entre in-

24 Víctor Hugo Acuña, Conflicto y Reforma en Costa Rica: 1940-1949, San José, Universidad Estatal a Distancia, 1992, pp. 17-18. 
tereses sociales contrapuestos o antagónicos. Las relaciones económicas que sustentaban el poder excluyente de los propietarios del capital tenían que sujetarse a las limitaciones de una sociedad pautada estatalmente por la libertad e igualdad de los desposeídos y por la determinación de un destino común. ${ }^{25}$

La política pública era una condición de la intervención del Estado social, pero no le pertenecía ni era una concesión, era un deber estatal por ser un derecho adquirido por los habitantes desde el mismo momento que conquistaron su ciudadanía. Los derechos ciudadanos tienen su correlato en el deber estatal de efectuar la política pública, estableciéndose así el nexo indivisible entre el individuo y la comunidad política. ${ }^{26}$ De esta manera, los ciudadanos participan plenamente de sus derechos civiles, políticos y sociales y retribuyen con obediencia y lealtad al Estado social, mientras se disfrutan y son respetados los derechos alcanzados colectivamente.

La igualdad, la democracia, la remuneración digna al trabajo, la protección laboral, el derecho a la educación, la salud o en general el gozar de servicios públicos subvencionados y tener prestaciones sociales, no han sido obsequios de gobernantes ni de partidos políticos, sino que han sido productos de luchas sociales, de enfrentamientos políticos y de antagonismos con formas estatales atrasadas. Ha sido una obra adquirida en íntima relación con la construcción de la ciudadanía.

El protagonismo del Estado no era una posición ideológica ni un capricho de gobernantes, sino producto de la propia evolución y desa-

25 Consideración que cuestiona las prácticas que con la nominación de política pública han homogeneizado prácticas iguales o similares en los ajustes estructurales aplicados en América Latina. Los ajustes estructurales fueron determinaciones ajenas y externas, que usaron al Estado para imponer acciones que negaban el interés y voluntad general de la sociedad, que violentaba la representación social y democrática del Estado, así como liquidar la política pública del Estado.

26 Jordi Borja, "La cuestión de la ciudadanía en el marco de las uniones políticas supraestatales: el caso europeo", VI Congreso Internacional del CLAD sobre la Reforma del Estado y de la Administración Pública, Buenos Aires, 2001. En http:// www.clad.org.ve. 
rrollo de las relaciones sociales, o la construcción del tiempo social en su espacio. ${ }^{27}$ La gestión y la política pública es una facultad restrictiva y subordinada a la sociedad civil.

El respeto a los derechos ciudadanos y el desarrollo de procesos democráticos eran las formas simbólicas del progreso de la sociedad y de la ideología necesaria del capitalismo. Sin embargo, la posición liberal costarricense no era de los propietarios del capital, del Estado ni de los liberales, ha sido una obra y una posición desarrollada y aceptada socialmente, que nutrió con las ideas de libertad y justicia social al Estado. ${ }^{28}$ El liberalismo contemporáneo se niega a sí mismo, al violentar su pasado y la constitución social de las libertades de los individuos en sociedad, así como los derechos de los pueblos a definir su propio destino.

La complejidad y diversidad de las relaciones que sustentaban al Estado se concretaban en la política pública, en una gestión cargada de contenido social e histórico, que de ningún modo fue neutro, técnico ni inmutable.

\section{EL ESTADO Y LA ADMINISTRACIÓN PÚBLICA}

En las políticas públicas no interviene cualquier Estado, ni tiene un estatuto independiente del Estado social, de modo similar la administración pública no es ajena ni extraña a las políticas públicas ni a su Estado, por el contrario, es el resultado de la configuración social del Estado, así como de la facultad de interpretar, planificar y de actuar en la sociedad, en razón de la construcción de un destino común entre clases desiguales.

${ }^{27}$ La intervención era una posición y la aplicación de una racionalidad para la regulación de la sociedad, como también fue observada por Kant, Hegel y Weber. La intervención a través de la política pública es una característica distintiva del Estado moderno, poseedor de una racionalidad arraigada indisolublemente al tiempo-espacio-sociedad.

28 Eugenio Rodríguez, pról., selec. y bibliografía, El pensamiento liberal. Antología, San José, Costa Rica, 1979; Eugenio Rodríguez y Luis Demetrio Tinoco, El pensamiento liberal costarricense, San José, Costa Rica, 1980 (Biblioteca Patria). 
La creencia de que todo Estado tiene la capacidad de hacer política pública es un supuesto que no discrimina el atributo social de los estados, ni tampoco establece diferencia entre la intervención del Estado social y el Estado privatizador, así como hace inconsistente y carente de significación social e histórica la noción de la política pública.

Siempre hubo un enorme debate sobre cómo se relaciona la sociedad y el Estado, cuál debería subordinar al otro y cuál debería encarnar los valores morales más elevados. De este modo, nos hemos acostumbrado a pensar que las fronteras de la sociedad y del Estado son las mismas o, si no, que podrían (o deberían) serlas. [...] Vivimos en estados. Hay una sociedad bajo cada Estado. Los estados tienen historia y, por lo tanto, tradiciones. [...] Esta imagen de la realidad social no era una fantasía. Tanto era así que los teóricos situados en perspectivas ideográficas y nomotéticas se desempeñaban con razonable desenvoltura, utilizando esos enfoques acerca de la sociedad y el Estado y logrando algunos resultados plausibles. El único problema era que, a medida que el tiempo pasaba, más y más "anomalías" se revelaban inexplicadas en ese esquema de referencia, y más y más lagunas (de zonas de la actividad humana no investigadas) parecían emerger. ${ }^{29}$

Las visiones predominantes sobre la administración la aprecian como una actividad técnica estandarizada, que toda organización debe aplicar, independientemente de la naturaleza de propósitos y actividades que realiza. Sin embargo, toda administración deberá estar pautada en razón de las características de las organizaciones. La aplicación estandarizada de procedimientos administrativos, no obtiene resultados predeterminados, porque la organización ni los medios sociales son objetos, sino sujetos del quehacer administrativo. La organización, con sus propósitos y características, es decisiva en la labor administrativa.

${ }^{29}$ Immanuel Wallerstein, "Unthinking Social Science", The Limits of NineteenthCentury Paradigms, Cambridge, Polity Press, 1991, p. 246. Tomado de Octavio Ianni, "Las ciencias sociales y la modernidad-mundo", en Robert Castel, Alain Touraine, Mario Bunge, Octavio Ianni y Anthony Giddens, Desigualdad y globalización. Cinco conferencias, Argentina, Facultad de Ciencias Sociales, Universidad de Buenos Aires y Ediciones Manantial, 2001, p. 88. 
En las organizaciones se podrán emplear técnicas administrativas, pero no serán independientes ni autónomas de las intencionalidades de cada organización, ni del contexto social donde se aplican.

El pragmatismo utilitarista predominante de las labores administrativas renuncia a la comprensión de las organizaciones, ignora la acción de las personas que las integran y del contexto donde funcionan e interactúan. ${ }^{30}$ Asimismo, se omite toda consideración histórica en el devenir de dichos entes sociales. La valoración de la técnica por la técnica misma, sin duda es un error a la luz de los conocimientos contemporáneos, así como es absurdo suponer que las organizaciones y las relaciones societales y orgánicas no están regidas por consideraciones culturales e históricas. El tiempo-espacio-sociedad no es un producto de la técnica, por el contrario, son las determinaciones sociales las que inciden en la viabilidad, pertinencia y existencia de la técnica. ${ }^{31}$

Las interpretaciones técnicas de la administración aún tienen continuidad en las concepciones sobre la política y la administración pública, a pesar de múltiples evidencias que lo cuestionan. La política pública, por ejemplo, regularmente es valorada en razón de los procedimientos de cómo se han configurado la agenda, las metas y los instrumentos empleados, sin ninguna referencia a la sociedad ni al Estado. Desde esa perspectiva, toda sociedad y cualquier Estado podrían hacer política pública, ${ }^{32}$ pues bastaría con cumplir con la formalidad preestablecida.

${ }^{30}$ Niklas Luhman, Organización y decisión. Autopoiesis, acción y entendimiento comunicativo, México, Universidad Iberoamericana y Editorial Anthropos, 1997.

31 Xavier Vence Deza, Economía de la innovación y del cambio tecnológico, Madrid, Siglo XXI, 1995; Juan Huaylupo, "La técnica en la economía y la investigación", Revista Economía y Sociedad, núm. 6, Heredia, Escuela de Economía. Universidad Nacional, 1998.

32 Charles Lindblom, El proceso de elaboración de políticas públicas, Madrid, Ministerio para las Administraciones Públicas/Instituto Nacional de Administración Pública, 1991; Luis Aguilar Villanueva, estudio introductorio y edición, La hechura de las políticas, México, Miguel Ángel Porrúa, 1994; Luis Aguilar Villanueva, estudio introductorio y edición, Problemas públicos y agenda de gobierno, México, Miguel Ángel Porrúa, 1993; Luis Aguilar Villanueva, estudio introductorio y edición, La implementación de las políticas, México, Miguel Ángel Porrúa, 1993; Joan Subirats, 
Sin embargo, una práctica estatal desarraigada de la naturaleza del Estado y de su sociedad, sin ninguna consideración ni mediación histórica, política o económica, sin duda, es un absurdo interpretativo que promueve prácticas caóticas y autocráticas.

La efectividad de la política pública y de la práctica administrativa institucional, no puede ser explicada en razón de la aplicación estandarizada de instrumentos o procedimientos, como regularmente se caracteriza a la burocracia o como se propone desde las pretendidas teorías administrativas ${ }^{33}$ Las prácticas administrativas del aparato institucional, no están desarraigadas del tiempo-espacio-sociedad inherente al Estado. El quehacer administrativo es la concreción de las relaciones históricas e interclasistas, así como de las costumbres y anhelos de la sociedad.

La subjetividad de la época y de la sociedad está presente en todo Estado y en cada práctica institucional, como diría Montesquieu, son "[...] las pasiones humanas que lo mueven". ${ }^{34}$ La voluntad y los sueños colectivos dan sentido y vida a las leyes y a las prácticas institucionales de las sociedades. Las regulaciones jurídicas y administrativas no suponen aplicaciones estandarizadas, porque son desiguales las circunstancias que las invocan y emplean.

El poder del Estado no es inmanente ni inherente a él, es un producto social y por tanto dependiente de los modos concretos de cómo se dirimen las relaciones entre los protagonistas sociales. El Estado tiene una relativa capacidad de conservación de las tendencias del pasado o en la reproducción de las relaciones imperantes. En todo caso, en su quehacer cotidiano no es ajeno al devenir de los procesos y acontecimientos que se dan en la sociedad civil.

Análisis de políticas públicas y eficacia de la administración, Madrid, Ministerio para las Administraciones Públicas, 1994; Carlos Losada i Marrodán [ed.], ¿De burócratas a gerentes? Las ciencias de la gestión aplicadas a la administración del Estado, Washington, Banco Interamericano de Desarrollo, 1999, entre otros.

33 Juan Huaylupo, La democracia, la burocracia y la autocracia. La reforma del Estado y el fin del bienestar, San José, Universidad de Costa Rica, 2003.

34 Montesquieu, Del espíritu de las leyes, México, Porrúa, 1982, p. 15. 
La presión para minimizar la presencia e influencia del Estado sobre el devenir de la sociedad, o la subrogación del Estado por las fuerzas sociales que hegemonizan las tendencias de la sociedad, ha sido una confrontación gestada y dirimida en el seno de cada sociedad civil, aún en procesos de integración mundial como en el presente.

La capacidad misma del Estado para intervenir lo vuelve un blanco atractivo para la influencia de intereses privados, y la capacidad misma de comprometerse abre la posibilidad de convivencia. De ahí que haya razones para esperar que la calidad de la intervención estatal en la economía dependa de la organización interna del Estado - en particular, de la relación entre políticos y burócratas - y el diseño de las instituciones democráticas que determinan si los ciudadanos pueden o no controlar a los políticos. ${ }^{35}$

La crisis del Estado benefactor es la manifestación del cambio en las relaciones de poder en la sociedad. El dinamismo de las relaciones sociales ha quebrado el equilibrio entre las desiguales fuerzas y protagonistas sociales. La capacidad para influir y condicionar el devenir social, político y económico ha sido alterado, así como el Estado liquida el equilibrio de una práctica social, benefactora y nacional, para convertirse en el ente que consolida las nuevas y arbitrarias relaciones de poder en la sociedad. El Estado ha sido efecto y causa de las transformaciones ocurridas en la sociedad.

El Estado social modificaba su influencia y poder en la sociedad civil, según se desequilibraban los poderes y capacidades orgánicas entre las clases sociales. La ruptura del equilibrio entre las clases o la profundización de las diferencias ante desarrollos sociales desiguales y poderes transnacionalizados, marcaba también el fin del equilibrio catastrófico de la práctica estatal. Las acciones del Estado, del presente globalizado, han dejado de ser garantes de la igualdad formal en la desigualdad social, para hacer transparente y sin ambigüedades su orientación clasista.

35 Adam Przeworski, "Acerca del diseño del Estado: una perspectiva principal-agente", Revista Argentina de Ciencia Política, núm. 2, Buenos Aires, 1998, p. 22. 
La transformación radical del Estado social ha sido paulatina y consistente, derivada de la pérdida de proyectos de vida, de desarrollo y de sociedad por parte de las clases subalternas, lo cual se ha correspondido con la relativa desaparición de su capacidad orgánica, de representación social o clasista de sus intereses e intersubjetividad por una sociedad democrática y solidaria. La libertad de los propietarios, no sólo se vincula con la ampliación de sus inversiones, sino también con la determinación del estilo de vida y el desarrollo nacional. Esa libertad arbitraria y unilateral de los empresarios es también una concesión de las propias clases subalternas que se han subordinado a proyectos sociales que alienan y cosifican su existencia, además de establecer una relación contradictoria de una libertad que se apropia de la libertad de los otros y que niega la interdependencia social. ${ }^{36}$

${ }^{36}$ Recientes acontecimientos en la sociedad costarricense ponen de manifiesto una corrupta red, en donde gerentes de transnacionales enriquecen, ilegal e ilegítimamente, a funcionarios y políticos para salir favorecidos con concesiones de obras públicas y adquisición de tecnologías. En estas prácticas corruptas están comprometidos gobiernos (Finlandia y España) que "generosamente" brindaban préstamos y cooperación internacional, para que se compraran equipos de sus países, los cuales eran eximidos de trámites y procedimientos legislativos, por influencia de diputados y ministros que se enriquecían con millones de dólares por concepto de comisiones y asesorías pagados por los prestamistas y por las empresas mundiales ganadoras de licitaciones. El resultado de tales compras fueron equipos más caros que los precios de mercado, además de haber resultado inservibles en unos casos e innecesarios, obsoletos y deficientes en otros. En http:/www.nacion.com/ln_ee/ESPECIALES/ccssfischel/home2.html.

En esta inmensa red que violenta el orden social y jurídico, se descubre también que el gobierno de Taiwán ha contribuido con miles de dólares al candidato presidencial en la campaña electoral del partido gobernante, así como depositaba millones a una empresa en otro país, de propiedad del anterior presidente de la República, personaje que ocupó efímeramente la Secretaría General de la OEA. En http://nacion.com/ ln_ee/2004/octubre/08/ultima_ce7.html. Al parecer el apoyo político costarricense en la disputa entre China y Taiwán ha sido interesado, así como lo es la infame e ilegal pesca en aguas costarricenses de aletas de tiburón por parte de barcos taiwaneses.

La protesta pública generalizada, convocada inéditamente por el Consejo Nacional de Rectores (Universidades estatales), efectuada el 12 de octubre de 2004, ha tenido una respuesta nacional de todos los sectores sociales no comprometidos con el poder político y empresarial dominante. La marcha pacífica fue denominada "Por la 
Los procesos que gestaron el Estado social en Costa Rica han perdido la fuerza y vitalidad democrática de su nacimiento. Las clases subalternas, sin capacidad organizativa, no tienen posibilidad de negociación ni de confrontación ante las fuerzas orgánicas del capital y del Estado. La división, o la atomización, de intereses en una atmósfera social individualista posibilita la realización de proyectos políticos, económicos y sociales ajenos a la colectividad nacional, sin oposición activa y significativa.

Asimismo, el dinamismo en las sociedades y en las relaciones internacionales creaba nuevas condiciones para la reproducción social, en donde el Estado social se transformaba en un agente subordinado de la fuerza, poder y organicidad del sector empresarial. El espacio de las relaciones políticas y económicas trascienden los ámbitos territoriales de las naciones, al crear nuevas configuraciones políticas en la sociedad y en la delimitación del poder estatal.

El globalismo contemporáneo ha impactado el quehacer cotidiano y nacional con relaciones que no son igualitarias ni equitativas. Las influencias mundiales están presentes, se funden y condicionan a los actores sociales en el espacio nacional. La libertad e igualdad empresarial globalizada logra no sólo independizarse del condicionamiento estatal para su crecimiento, sino que supedita el Estado a sus intereses. Como en otros tiempos, que los empresarios se liberaban de la especialización y trabajo del artesano para convertirlo en un proletario sin control del proceso ni de los productos del trabajo, ${ }^{37}$ en esta oportunidad la pre-

Dignidad Nacional y la Institucionalidad Democrática", en la cual no se permitió la presencia del actual presidente de la República ni la del contralor general de la República, que pretendían usurpar, con su presencia, una demanda popular y democrática. La Nación, San José, 13 de octubre, 2004.

La revelación de la corrupción de la clase política y el repudio social está posibilitando el rescate de la legitimidad al sistema judicial costarricense, que actúa sin la determinación política partidaria ni gubernamental, rompiendo con la impunidad y el cinismo de quienes se apoderan del aparato estatal, denigrando la representatividad democrática y la función pública.

37 La obra y práctica de Frederick Taylor en parte sintetiza la conversión de los artesanos en proletarios. 
eminencia del capital mundial sobre el nacional posibilita la captura del poder estatal, para subsumirlo realmente a la lógica de la valorización del capital mundial.

[...] la sociedad global recubre, asimila o subsume a la sociedad nacional en una realidad que todavía no esta suficientemente reconocida y codificada. La sociedad global presenta desafíos empíricos y metodológicos, o históricos y teóricos, que exigen nuevos conceptos, categorías e interpretaciones. ${ }^{38}$

La representación social y clasista del capital se autonomiza, no sólo de la condicionalidad económica y política del Estado, sino también se desarraiga de la voluntad, intereses y aspiraciones de los trabajadores y desposeídos del medio, así como desecha y desprecia toda proposición en torno de una propuesta compartida y nacional de desarrollo.

La conversión del Estado social en un Estado privado es una transformación reaccionaria, es una vuelta caricaturesca al pasado, así como la renuncia expresa y manifiesta a la relativa autonomía clasista, para subsumirse a la voluntad de los propietarios del capital mundializado. Las aspiraciones nacionales, el desarrollo, el bienestar, en esencia pluriclasistas e interdependientes, han sido reducidas a los logros empresariales. Las más altas jerarquías del poder estatal han identificado el enriquecimiento empresarial con el bienestar nacional o han subordinado el desarrollo y el bienestar social al crecimiento de las ganancias de empresarios mundiales.

En la transformación del Estado social también han intervenido poderes internacionales, evidenciados con las condiciones políticas y económicas impuestas por los organismos internacionales. Los mellizos de Bretton Wood, el Fondo Monetario Internacional y el Banco Mundial han sido actores privilegiados en los procesos de la transnacionalización norteamericana de las economías y en el debilitamiento y liquidación del Estado social en las realidades latinoamericanas, proceso al que se suma, contemporáneamente, la acción del Banco Interamericano de Desarrollo y el Banco Centroamericano de Integración.

38 Ianni, op. cit., p. 88. 
De manera particular, los Programas de Ajuste Estructural impulsados y aplicados en la década de los años ochenta fueron intervenciones internacionales, con la mediación estatal, para la imposición de acciones destinadas a reorientar la economía nacional e intensificar las transferencias de valor, riquezas y recursos, a través del pago de la deuda externa, concesiones y procesos de privatización.

El Estado costarricense, al no tener ninguna capacidad para determinar la orientación de su intervención sobre la sociedad, ha perdido la facultad de hacer política pública, de actuar y garantizar lo público, de paliar las desigualdades, inequidades e incluso ha perdido la capacidad para amparar y defender los derechos igualitarios de los ciudadanos.

Esta situación, creo, ha cambiado profundamente; y podríamos incluso calificar este cambio, diciendo que hemos pasado de una dinámica regulada de las desigualdades, que hemos descrito, a una dinámica desregulada de las desigualdades. ${ }^{39}$

Hoy la ciudadanía se enfrenta a un doble desafío. Por una parte, hay factores que ponen en cuestión los contenidos de la ciudadanía adquirida. Por otra parte, nuevos fenómenos plantean la necesidad de ampliar los contenidos y renovar el concepto de ciudadanía.

Entre los factores que cuestionaban la ciudadanía los más importantes son los que resultan de la crisis de los Estados de Bienestar y del aumento persistente del desempleo. En los países europeos una parte creciente de la población pierde progresivamente sus atributos de ciudadanía: no vota, no tiene trabajo, vive en zonas marginales, se siente excluida de las instituciones, no está conectada con el progreso de las redes de comunicación, de modo que se genera un "out", que es peor que estar "abajo". Esta situación se agrava porque entre los ciudadanos con probabilidad de ejercer "sus derechos" el temor a quedar fuera estimula los comportamientos corporativos insolidarios, la intolerancia, la xenofobia. A lo cual hay que añadir que una parte significativa de la población no pierde la ciudadanía porque nunca la ha tenido $[\ldots] .{ }^{40}$

39 Robert Castel, "Empleo, exclusión y las nuevas cuestiones sociales", en Castel, Touraine, Bunge, Ianni y Giddens, op. cit., pp. 18-19.

${ }^{40}$ Borja, op. cit., p. 10. 
La otrora sociedad costarricense, ejemplo temprano de un Estado social, se ha transformado en un Estado autonomizado de su sociedad civil. ${ }^{41} \mathrm{Ha}$ ocurrido un golpe de Estado, ${ }^{42}$ que niega el pasado e instaura una autocracia, sin coherencia ni consistencia ideológica, política, ética ni social. La liquidación de la planificación y de la política pública ha creado una nominal administración pública caótica, corrupta y desarticulada, en donde el uso privado de los recursos y facultades institucionales se ha convertido en una regularidad, antes que una excepción. Habría que mencionar, también, que este proceso ha creado la posibilidad del irrespeto a la autoridad estatal por parte de la colectividad, ante la trasgresión de los derechos, voluntad y aspiraciones ciudadanas por parte de un poder legal pero ilegítimo. ${ }^{43} \mathrm{El}$ contexto costarricense, conservador y estable, comienza a cambiar para manifestarse con recurrentes protestas gremiales y sectoriales, repudio a los gobernantes y diputados, desconfianza a la institucionalidad y creciente indiferencia por las opciones políticas partidarias de todos los signos ideológicos.

El nuevo Estado privatizador abriga las contradicciones e incertidumbres del capital y desarticula la interdependencia, requisito esencial de la reproducción del capital y del propio Estado. ${ }^{44}$ La pretensión de crear un Estado sin tiempo-espacio por el imperio del poder político y económico, sólo tiene validez en la coyuntura, dado que no posee la

${ }^{41}$ Alicia Calvo, "Privatizaciones y captura del Estado", VI Congreso Internacional del CLAD sobre la Reforma del Estado y de la Administración Pública, Buenos Aires, Argentina, 5-9 de noviembre, 2001.

${ }^{42}$ Las prácticas del fugitivo y ex gobernante del Perú, Fujimori o Menen en Argentina, son algunas de las manifestaciones que transformaron el orden constituido y violentaron el pasado nacional, como también ocurre en Costa Rica. Los procesos autocráticos y tiránicos en América Latina están articulados con prácticas globales concentradas y centralizadas del patrimonio público y estatal.

${ }^{43}$ Las protestas en las calles, tan extraño en la tradición y cotidianidad política costarricense, se está convirtiendo en casi el único medio posible para negociar y hacer respetar las reivindicaciones y derechos conquistados.

${ }^{44}$ Franz Hinkelammert, El asalto al poder mundial y la violencia sagrada del imperio, San José, Departamento Ecuménico de Investigaciones (DEI), 2003. 
consistencia para dar continuidad, legitimidad ni estabilidad a las propias relaciones capitalistas.

La conformación de estados que niegan la historia y los sueños de los protagonistas heterogéneos de sus pueblos es un proceso que tiende a generar nuevas tensiones y contradicciones en Costa Rica, Perú, Argentina, Bolivia o Venezuela en nuestra América Latina. El individualismo posesivo predominante ha creado otra fuente de inestabilidad e inequidad, ${ }^{45}$ que denigra la función pública, anula todo vestigio democrático, así como pauperiza y desfalca la calidad de vida de las poblaciones. ${ }^{46}$ La reconstitución de la viabilidad social y política de las relaciones económicas capitalistas deberá recomponer y socializar el bienestar alcanzado por la sociedad mundial, como un requisito para su propia reproducción.

En los últimos diez años ha habido un aumento extraordinario de la desigualdad social, la pobreza y la exclusión en la mayoría de los países, incluido Estados Unidos. Por eso los límites de este sistema no son económicos o tecnológicos: son sociales y políticos. Pero debido a la deslegitimación creciente de las instituciones del Estado, las explosiones y movimientos sociales son hoy por hoy los únicos límites a ese sistema altamente dinámico y creativo, pero al mismo tiempo altamente excluyente y destructivo. ${ }^{47}$

45 Ernesto Castagnino, "Reformas del Estado y políticas públicas en el área social: ¿contraposición o convergencia?", VII Congreso Internacional del CLAD sobre la Reforma del Estado y de la Administración Pública, Lisboa, 2002.

46 La práctica contemporánea contrasta con la propuesta que hizo sir William Beveridge, en las postrimerías de la Segunda Guerra Mundial (1942), que para evitar que la situación de Gran Bretaña retrocediera a las inequidades del siglo XVIII, ideaba un sistema de solidaridad entre clases sociales, entre empleados, empleadores, desempleados y trabajadores independientes. Juan Huaylupo, "La política pública en un contexto de privatización de la política social del Estado", Revista Mexicana de Sociología, núm. 4-99, México, IIS-UNAM, 2000.

${ }^{47}$ Manuel Castells, "Entrevista de Carlos Chamorro a Manuel Castells", Revista Ajoblanco, octubre, 1999. En http://www.diaridebarcelona.com/coneheme/castells. htm, 12 de diciembre, 2003. 
Asimismo, las brechas tangibles entre segmentos y clases sociales están provocando separaciones en los estilos de vida, cultura, consumos y aspiraciones entre las poblaciones. La disgregación o atomización de las sociedades limita la posibilidad de construir proyectos nacionales, como potencia la viabilidad política al poder constituido.

Hay una dimensión subjetiva del cambio social que se vislumbra en la ampliación de las distancias reales y relativas entre distintos sectores sociales visibles en la disposición cada vez más desigual de activos físicos (infraestructura habitacional, transportes, recreo, educación, salud y seguridad pública). También es visible en la disposición de medios políticos de cambio, como se deduce de la tendencia a la elitización de las representaciones políticas. ${ }^{48}$

La recomposición de la política pública es una necesidad social, política y económica, tanto en el espacio-tiempo nacional, como mundial. Las determinaciones globales en la situación de los países exigen decisiones y acciones perentorias que compensen las transferencias, el desfalco del trabajo humano y la riqueza de los países pobres del mundo. ${ }^{49}$

\section{LA REFORMA DEL ESTADO: UNA TRANSFORMACIÓN DEL PODER SOCIAL}

La reforma del Estado ha sido un discurso y una práctica desde que fue considerado ideológicamente como la causa de todos los problemas de la sociedad. La irrupción conservadora de los gobiernos de Ronald

48 Naciones Unidas, Evaluación común de país: Costa Rica, San José, 2000, p. 19.

49 James Tobin premio Nobel de economía propuso en 1972 un impuesto de $0.5 \%$ a las transacciones financieras especulativas en el mundo (conocido como la tasa Tobin), como un medio para paliar los desequilibrios críticos de los países pobres. Esta propuesta inviable ante el cuestionamiento de Estados Unidos y el Fondo Monetario Internacional. Jesús Lizcano Álvarez, "La tasa Tobin, mitos y realidades", El País, España, 9 de febrero, 2001; "Jospin y Tobin", El País, España. 30 de agosto, 2001; "El movimiento antiglobalización abusa de mi nombre", El País, España, 3 de septiembre, 2001; "Tobin reclama su tasa", El País, España, 5 de septiembre, 2001; "Los gobernadores de los bancos centrales, contra la 'tasa Tobin'”, El País, España, 8 de septiembre, 2001. 
Reagan en Estados Unidos y de Margaret Theacher en Gran Bretaña, no sólo pretendían desregular sus sociedades, sino incluso controlar el mundo, al querer reeditar la Guerra Fría para reconstruir hegemonías debilitadas y polarizar el planeta. $^{50}$

La reforma del Estado o la liquidación de la forma estatal que regulaba la sociedad, no ha sido una opción original en América Latina, ni un resultado del análisis y evaluación de las determinaciones de la problemática económica o social de nuestras realidades. ${ }^{51}$ Desde la década de los años ochenta ha sido una propuesta condicionada externamente y apropiada por los estados que usurparon y violentaron la representación democrática y el respeto a los derechos ciudadanos.

La reforma del Estado es una contrarrevolución a la constitución del Estado social, contra su injerencia en la economía, en la política y en el devenir del desarrollo nacional. Es la instauración del Estado privatizador del bienestar, del fin de la regulación de la desigualdad, del laissez faire, laissez paseé, o la desregulación de la pobreza, de la riqueza, del bienestar, del desarrollo, de la calidad de vida de los actores sociales.

Los argumentos del liberalismo contemporáneo, discursivamente contrarios a la intervención y al condicionamiento de la libertad de decisión de los actores privados, así como opositor a la alteración del devenir de las tendencias sociales, es tan sólo aparente, dado que la Reforma del

50 El poder hegemónico de las potencias económicas y militares, del pasado y presente, al imponer sus intereses sobre la colectividad mundial, de ningún modo supone vaciar de contenido las relaciones creadas espacial, temporal y societalmente. Es absurdo imaginar la homogenización del devenir de los pueblos a la lógica posesiva del poder mundial, como tampoco tiene posibilidad histórica la subordinación de las sociedades y estados a los dictados de ese poder.

Las contradicciones que generan las imposiciones norteamericanas a la comunidad de naciones y a gobiernos que privatizan la representatividad, el interés general y la función pública, es un reto contemporáneo de la colectividad mundial, que aún no cuenta con la medios ni la fuerza que contenga, sin la fuerza de las armas, la expansión militar norteamericana.

51 El Consenso de Washington en 1990 plantea explícitamente no sólo la desregulación estatal, la apertura comercial y la flexibilización laboral, también la Reforma del Estado. 
Estado no es la conversión de la proactividad del Estado social en un ente contemplativo y observador de lo que ocurre en la sociedad, por el contrario, es la reorientación de la actividad del Estado en un sentido inverso al Estado social. El Estado privatizador está promoviendo la concentración y centralización del capital, a través del incentivo, subsidio y la privatización de la función pública, mientras que los trabajadores, los desocupados y los pobres, no sólo deben procurarse los medios para la subsistencia y la vida sin el apoyo ni protección del Estado, sino que deben soportar cargas impositivas y desfalcar el valor del trabajo para el beneficio del capital, con la mediación estatal. Esta práctica estatal es activa y contribuye de modo directo e intencionado al incremento de la riqueza, así como también de la pobreza en el presente y en el espacio de la sociedad latinoamericana en general y costarricense en particular.

El Estado privatizador para justificar su acción alejada del bienestar de los pobres, ha argumentado que la protección estatal es la causa por la cual se impide que las poblaciones busquen alternativas para superar sus condiciones de pobreza, como si la precariedad social fuera una decisión y voluntad de los excluidos. El cinismo empresarial, convertido hoy en la clase política, justifica el subsidio y protección estatal a la rentabilidad de las inversiones privadas, pero niega el gasto público en los pobres y en los servicios públicos.

La apropiación privada de los excedentes generados colectivamente en los procesos productivos empresariales, se han complementado, en el presente costarricense, con la privatización del uso de los recursos públicos y del poder formal del Estado. La reducción de impuestos, la devaluación diaria, el endeudamiento externo para propósitos privados, la concesión de la obra pública, la impunidad para la clase política y económica, ${ }^{52}$ o el enriquecimiento ilícito de los recursos captados por el

${ }^{52}$ Los fraudes de los empresarios por recibir subsidios a través de Certificados de Abono Tributario, falsificaron los volúmenes y valores de sus exportaciones. Asimismo, partidos y personajes políticos que violentan la Ley que regula el financiamiento de actividades proselitistas, permanecen impunes. José Merino del Río, El fraude con los CAT: un asalto millonario a los dineros del Estado, Propuesta de Informe de la 
Estado para paliar la pobreza, ${ }^{53}$ etc., son algunas de las expresiones de la privatización de la función pública del Estado privatizador costarricense.

La orientación clasista del Estado se materializa en Costa Rica con el nombramiento de empresarios como ministros y directores de instituciones públicas. Los propietarios privados conducen las organizaciones al mejor estilo empresarial, maximizan los recursos materiales, sobreexplotan el trabajo humano y hacen que los servicios estatales sean superavitarios. ${ }^{54}$ De este modo, el gasto público se convertía en inversión, así como se transformaba en ganancias para las organizaciones privadas que proporcionaban algunos servicios públicos, como los cuasimercados en la salud pública. ${ }^{55}$ El Estado privatizador no sólo ofrece las condiciones para la rentabilidad privada, también se ha convertido en un redistribuidor de los recursos públicos hacia las organizaciones empresariales, ${ }^{56}$ un ejemplo de ello han sido los préstamos para los concesionarios privados de las obras públicas.

Comisión Especial que investiga los Certificados de Abono Tributario, San José, Asamblea Legislativa de la República de Costa Rica/Editorial Juricentro, 1999.

Asimismo, recientemente se ha revelado que importantes personajes políticos, incluido un ex presidente de la República y dirigente del partido en el poder político, un ex diputado, el jerarca de la Caja Costarricense de Seguro Social, entre otros, se encuentran comprometidos con un reparto ilegal de millones de dólares de un préstamo otorgado por el gobierno de Finlandia (septiembre, 2004).

53 José Merino del Río, El desastre de FODESAF: una operación ilegal para lucrar con el dinero de los más pobres, Informe al Parlamento y a la Ciudadanía, San José, Asamblea Legislativa de la República de Costa Rica/Editorial Juricentro, 1998.

54 Edgar Varela Barrios, "La mercantilización de lo público", VII Congreso Internacional del CLAD sobre la Reforma del Estado y de la Administración Pública, Lisboa, Portugal, 8-11 de octubre, 2002. En http://www.clad.org.ve.

55 Ana Sojo, "Reformas de gestión en salud en América Latina: los cuasimercados de Colombia, Argentina, Chile y Costa Rica", Serie Políticas Sociales, núm. 39, Santiago de Chile, Comisión Económica para América Latina y el Caribe/Naciones Unidas, 2000, y "Hacia unas nuevas reglas del juego: los compromisos de gestión en salud de Costa Rica desde una perspectiva comparativa", Serie Politicas Sociales, núm. 27, Santiago de Chile, Comisión Económica para América Latina y el Caribe/ Naciones Unidas, 1998.

56 Daniel Aspiazu, "Privatizaciones y regulación pública en la Argentina: captura institucional y preservación de beneficios extraordinarios", VI Congreso Internacio- 
La reforma del Estado ha reestructurado el poder estatal en las sociedades latinoamericanas, y particularmente en Costa Rica, pero lo ha modificado en las cúspides del poder, en su representación social, pero de ningún modo ha podido borrar la construcción histórica y societal que otorgó legitimidad y pertinencia al Estado social. El Estado privatizador del presente no es una construcción colectiva, es la posesión en el aparato estatal de un poder excluyente y unilateral. No ha existido una involución individual y privada de los procesos productivos y sociales, por el contrario, la socialización y la interdependencia es cada vez mayor. No se han borrado ni reemplazado las bases y condiciones que propiciaron la constitución del Estado social. La impronta del espacio-tiempo-sociedad que crearon un Estado democrático y representativo de la heterogeneidad social en Costa Rica no ha sido sustituido. $\mathrm{El}$ asalto al poder formal del aparato estatal no ha eliminado el sustento social del Estado costarricense.

A través de la Reforma del Estado, los empresarios transnacionalizados se han apropiado ilegítimamente del poder social, han asaltado la legalidad ${ }^{57}$ y la formalidad del poder estatal para imponer la dictadura del capital mundializado en el espacio-tiempo latinoamericano. El poder empresarial pretende privatizar la historia social y el desarrollo nacional, ha convertido el aparato del Estado en la formalización de su poder, al usar la corrupción y el chantaje como mediación y transfiguración de su poder económico.

La Reforma del Estado garantiza el crecimiento económico con degradación de la cultura, del conocimiento, del trabajo, de la función pública y de la calidad de vida de los pueblos. Es la manifestación coyuntural del

nal del CLAD sobre la Reforma del Estado y de la Administración Pública, Lisboa, 2002. En http://www.clad.org.ve.

57 Las leyes inmorales que cuestionan el derecho público, que transgreden la legitimidad y violentan el orden legal establecido, es una regularidad en el ejercicio arbitrario del poder, que también ha controlado la libertad y autonomía del poder judicial. El Estado se privatiza legal pero ilegítimamente, reeditándose la expresión de Séneca: "Non omne, quod liceo, honestum est" (La ley permite lo que la honestidad rechaza). 
triunfo de la contrarrevolución política, con los símbolos e instrumentos del poder económico.

\section{LA REFORMA INSTRUMENTAL DEL ESTADO Y LA NUEVA GESTIÓN PÚBLICA}

Las críticas a la efectividad, burocracia y rigidez de la actuación del Estado han sido atribuidas a la forma de organización, estructuración y funcionamiento del aparato institucional. La inoperancia de las instituciones del Estado han sido apreciadas desde los procesos administrativos, sin consideración alguna de las determinaciones jurídicas, de las formas políticas, de como han sido manejadas las instituciones, de las modificaciones y complejidad de los ámbitos sociales de la actuación institucional del Estado.

La práctica administrativa del Estado ha sido analizada desde los propios procesos administrativos, sin tomar en cuenta que los resultados de sus intervenciones tienen determinaciones políticas, económicas, jurídicas y sociales, que condicionan la efectividad de su quehacer. El largo historial de fracasos de las aplicaciones instrumentales y técnicas en la administración pública confirman que los problemas del quehacer estatal trascienden las prácticas administrativas, sin embargo, las jerarquías del poder estatal, así como los órganos empresariales prefieren culpar a los funcionarios públicos, a la cultura organizacional y a las propias organizaciones públicas, como responsables de la precaria funcionalidad de la actuación del Estado.

La intencionada interpretación sobre la obsolescencia, productividad, eficacia y eficiencia del Estado, alimentada por la opinión publicada, ha servido de justificación para la reducción del gasto público y del aparato estatal, así como en la disminución de su capacidad de condicionamiento económico, al eliminar la absorción y estabilidad laboral, así como haber implantado la flexibilización y el desempleo para los funcionarios públicos. Asimismo, esas pretendidas reformas promueven un mayor deterioro en la movilidad de capitales y la inversión pri- 
vada, al mismo tiempo se pretende que el trabajo público sea más regulado y evaluado en razón de estándares de otros países. Las reformas están directamente relacionadas con los intereses empresariales, en perjuicio de la función pública y del proceso de empobrecimiento.

Las concepciones y prácticas economicistas, que son manifestaciones que atribuyen automatismos a las relaciones económicas, ${ }^{58}$ niegan las determinaciones históricas, sociales, políticas e ideológicas que están presentes en la economía, como en las relaciones de reproducción de la sociedad, lo cual es una simplificación insostenible a la luz de los conocimientos en la economía, en las ciencias sociales y en la epistemología contemporánea. La búsqueda de rentabilidad y liquidez en la práctica empresarial doméstica y estatal ha buscado y logrado la flexibilidad burocrática para maximizar la ganancia privada y la generación de excedentes en el ejercicio institucional de la función pública. ${ }^{59}$

Una reforma estatal e institucional que adopta decisiones sustentadas en erróneos conocimientos sobre las realidades que actúan e inciden en la complejidad nacional y mundial, es una forma para hacer aún más imprevisibles y caóticos sus efectos. ${ }^{60}$ Los procesos de reforma del

58 Entre las evidencias recientes de las prácticas economicistas en el quehacer estatal costarricense se encuentran la centralidad y focalización por aprobar en un año el Tratado de Libre Comercio con Estados Unidos, proceso que contrasta con los once años que duró en Chile. Asimismo, está el esfuerzo por aprobar una reforma tributaria que profundiza el carácter regresivo del sistema. Ambos aspectos han sido señalados, por el gobierno y los empresarios, como vitales y esenciales para la economía y la sociedad.

59 En Costa Rica se exige que el Instituto Costarricense de Electricidad (ICE), la Caja Costarricense de Seguro Social (CCSS), Instituto de Acueductos y Alcantarillado (AyA), Instituto Nacional de Seguros (INS) o el Instituto Nacional de Aprendizaje (INA), se les impone la generación de excedentes para ser usados en las prioridades del poder Ejecutivo, en donde los desequilibrios macroeconómicos, el pago de la deuda interna y externa y el incentivo privado, son privilegiados frente al gasto social en bienestar social.

60 Edgar Varela Barrios, "La transformación de la burocracia pública: una perspectiva crítica del proceso de reforma del Estado en América Latina, 1980-2001", VI Congreso Internacional del CLAD sobre la Reforma del Estado y de la Administración Pública, Buenos Aires, 2001; José Chanes Nieto, "Alcances y límites de la reforma del Estado", VI Congreso Internacional del CLAD, Buenos Aires, 2001. 
Estado muestran evidencias tangibles y permanentes de la radicalización de la opción política adoptada, lo cual ha incidido directamente en el retroceso de los logros alcanzados por la sociedad contemporánea. ${ }^{61}$

La Nueva Gestión Pública (NGP o New Public Management), ${ }^{62}$ que se promueve para la Reforma del Estado, ${ }^{63}$ no es otra cosa que la aplicación de técnicas y procedimientos de la gestión pública que imitan a los utilizados en la administración privada, para, supuestamente, hacer eficiente y eficaz la actividad del Estado.

En la actualidad se observa en todo el mundo una tendencia a mejorar la administración pública utilizando conceptos, herramientas y técnicas de gestión surgidas en muchos casos para resolver problemas del sector privado. De cualquier manera, para que la gestión pública prospere como sector en crecimiento no podemos limitarnos simplemente a extrapolar el planteamiento que sirvió de base a sus éxitos iniciales, pues están apareciendo problemas nuevos y diferentes para los cuales no tenemos respuestas prefabricadas. Resulta ya preocupante que, por norma general, las

${ }^{61}$ El incremento de la pobreza, así como la evidencia de la existencia de pobreza absoluta en América Latina, como lo muestran diversos estudios efectuados por la Comisión Económica para América Latina y el Caribe (CEPAL), son las manifestaciones del retroceso, de más décadas, en los indicadores sociales. Esta situación ha convertido a esta parte del continente americano en el espacio social de mayor polaridad social del mundo.

62 “' 'El nuevo gerencialismo' (New Public Management —NPM-) se basa en un conjunto de discusiones sobre la transición desde un paradigma burocrático de administración pública hacia un nuevo paradigma gerencial que considere las transformaciones en el medio e incorpore instrumentos gerenciales probados con éxito en el mercado". Sonia Fleury, "Reforma del Estado", Diseño y gerencia de políticas y programas sociales, Washington, Instituto Interamericano de Desarrollo Social/Banco Interamericano de Desarrollo, 2002, p. 11.

${ }^{63}$ Juan Huaylupo, "La gerencia social en la transformación del Estado", Sistema integrado y analítico de la información sobre Reforma del Estado, gestión y políticas públicas (SIARE), Centro Latinoamericano de Administración para el Desarrollo (CLAD), 2003. En http://www.clad.org.ve; Ben Ross Schneider, "La política de la reforma administrativa: dilemas insolubles y soluciones improbables", Revista Reforma y Desarrollo, núm. 20, Caracas, 2001; David Arellano Gault, "Nueva gestión pública: ¿el meteorito que mató al dinosaurio? Lecciones para la reforma administrativa en países como México", Revista Reforma y Desarrollo, núm. 23, Caracas, 2002. 
soluciones a los problemas de gestión sean más previsibles que los problemas mismos que ésta intenta resolver. [...] Es preciso revisar el programa de reforma para tener en cuenta los rasgos distintivos de la gestión pública, pues su transformación no consiste simplemente en una búsqueda apolítica de eficiencia técnica dentro de un marco institucional dado. ${ }^{64}$

El haber robotizado el trabajo humano para elevar la capacidad productiva del trabajo individual y colectivo, así como el haber eliminado las sensibilidades y habilidades del trabajador en los productos de su trabajo fue un logro para los empresarios, porque les permitió el control del proceso laboral, al despojar de esa facultad a los trabajadores que conocían y confeccionaban los productos. ${ }^{65}$ En el presente, también los empresarios se han liberado de las prácticas burocráticas y de las condicionalidades que imponía el Estado social.

La práctica tecnocrática establecida desde finales del siglo XIX, no sólo fue un acto económico, sino una determinación política en el ámbito del dominio privado, cuyo horizonte ideológico aún llega a nuestros días. Así, en la función y gestión pública, en las dos últimas décadas, el Estado no ha tenido medio alguno ni social ni cognoscitivo para limitar la acción tecnocrática que invadía la práctica pública, por considerar que es el único medio para la modernización, la reforma y optimación del quehacer estatal, lo cual son variantes contemporáneas que desprecian el trabajo humano del siglo XVIII.

La magnificación de las prácticas tecnocráticas aprecian a los individuos, grupos, organizaciones, culturas y sociedades como objetos, pasivos e inertes de las aplicaciones técnicas. El arrogar a la técnica las capacidades de transformación es una visión inductivista ingenua, que ignora la historia y la construcción social del espacio.

${ }^{64}$ Les Metcalfe, "La gestión pública: de la imitación a la innovación", en Losada i Marrodán, op. cit., pp. 47-48.

65 Este acontecimiento organizativo y productivo que Frederick Taylor y Henry Fayol desarrollaron y que sus continuadores denominaron como la administración científica del trabajo. 
Desde esa perspectiva, no se toma en cuenta ninguna consideración relacionada con la historia, cultura, sociedad, seres humanos o naturaleza de las cosas para valorar por sí y en sí misma a la técnica. La valoración absoluta de la técnica es insustentable, teórica y empíricamente, sin embargo, es un dogma para quienes la practican, pues no escuchan razones ni observaciones. La alienación a la técnica ignora que el tiempo-espacio-sociedad es lo que da viabilidad, pertinencia y consistencia a las aplicaciones, como a sus resultados.

La elevada ponderación a los procesos mecánicos ha deshumanizando las relaciones sociales para importar sólo el momento y el resultado de las aplicaciones. Las relaciones en las organizaciones, en la producción o en la vida social crean las condiciones para el surgimiento y viabilidad de la técnica, porque le proporcionan las bases y las circunstancias materiales para que ésta pueda ser creada, producida y aceptada.

A la luz del prejuicio técnico, el Estado se revela como un aparato que tiene una estructura organizativa y de funcionamiento, que puede ser alterada por las aplicaciones técnicas, así como modificable según pautas jurídicas de acatamiento obligatorio. De este modo, las valoraciones en torno a la técnica, en el proceso de reforma estatal, podría ser sintetizada como la forma fetichizada con la que se encubren las orientaciones políticas y económicas del poder estatal en las instituciones públicas y la sociedad. Los modos como se impone el hacer estatal es una facultad arrogada de la legalidad del pasado estatal costarricense por parte del Estado privatizador.

La transformación radical del Estado ha contribuido a la descomposición de los logros sociales que se alcanzaron al construir un Estado social. En Costa Rica fueron algo más de cuarenta años de vigencia del Estado social, que contribuyó a conformar una sociedad democrática con desarrollo institucional, respeto a la legalidad, resguardo a las garantías ciudadanas y la elevación de la calidad de vida. La liquidación del Estado social ha marcado un retroceso en todos los ámbitos sociales.

Ante esta situación, la reconstitución del Estado es una necesidad para la reproducción de la sociedad, que trasciende a las aplicaciones técni- 
cas y el pragmatismo utilitarista empresarial. La refundación social del Estado y de la política pública y la administración, no podrá ser la reedición del Estado social del pasado, sino la construcción de una inédita relación donde todas las clases sociales sean protagonistas de un destino compartido, sin la centralidad de partidos políticos ni del Estado.

La búsqueda de alternativas de acción y organización de los grupos desde la sociedad civil, sin la presencia del Estado ni de empresarios posesivos y excluyentes, ya es una realidad ${ }^{66}$ y una tendencia que si bien, aún no es predominante ni reguladora del devenir colectivo, es una alternativa y una posibilidad democrática y pluralista.

Las clases subalternas tienen la potencialidad de gestar una nueva unidad social e histórica. Las fuerzas sociales emprendedoras del pasado, asociadas con el crecimiento y expansión del capital, son reaccionarias y sin sustento social en el presente. Una vida social libre del individualismo posesivo y de la alienación del capital y de la técnica es el nuevo reto en la construcción de una sociedad y un mundo con rostro humano.

\section{A MODO DE REFLEXIÓN FINAL}

Las reflexiones efectuadas permiten afirmar que en las ciencias sociales las consideraciones de tiempo-espacio no han estado alejadas ni han sido extrañas a su quehacer investigativo, tampoco han sido prácticas generalizadas en el quehacer académico y profesional de algunas especialidades, como la economía, la administración o los negocios.

66 Bernardo Kliksberg, "Capital social y cultura. Claves olvidadas del desarrollo", $H a$ cia una economía con rostro humano, Paraguay, Desarrollo/Instituto de Capacitación y Estudios, 2003; Joseph Stiglitz, El malestar en la globalización, Colombia, Taurus, 2002; José Real Dato, "Visiones sobre el papel de los actores no gubernamentales en la políticas públicas", VII Congreso Internacional del CLAD sobre Reforma del Estado y de la Administración Pública, Lisboa, 2002; Joseph Stiglitz, "Más instrumentos y metas más amplias para el desarrollo. Hacia el Consenso Post-Washington", Revista Reforma y Desarrollo, núm. 12, Caracas, 1998. 
Las interacciones humanas no transcurren con independencia de los espacios ni de los tiempos o épocas de las sociedades, los cuales no son iguales ni similares entre las sociedades. Todas las relaciones sociales suponen e implican relaciones con su espacio-tiempo-sociedad. La supeditación del tiempo a la sociedad y la significación cultural, económica o ambiental del espacio, de ningún modo supone su omisión analítica, por el contrario deberán estar presentes porque se encuentran integradas a las relaciones sociales.

La reconstrucción por la vía del pensamiento del tiempo de las organizaciones y sociedades es un requerimiento imprescindible en las investigaciones, por ser una consecuencia de las relaciones construidas socialmente, las cuales otorgan significación particular a los procesos. Los acontecimientos y atmósfera vividos en Costa Rica antes de la década de los años cuarenta fueron la construcción de una época que desembocaría en la Guerra Civil de 1948, la cual marcaría el surgimiento de una nueva forma estatal y consolidaría inéditamente una sociedad moderna en el espacio centroamericano, así como en la década de los ochenta nuevos actores en circunstancias distintas, reestructuran la economía, el Estado y la política pública. Esto es, han sido momentos que no son reproducibles en la historia nacional, que pertenecen solamente a las circunstancias particulares que las gestaron.

La década de los años cuarenta en Costa Rica estuvo marcada por una coyuntura que sintetizaba la actuación de todos sus actores sociales en aquel espacio-tiempo, y en donde la explicación parcial, segmentada y disciplinaria no podía explicar ni comprender los fenómenos que se presentaban integrados, no sólo en los grandes eventos, sino permanentemente.

Analizar las orientaciones de la sociedad como una totalidad configura el espacio-tiempo-sociedad, donde se desenvuelven todas las prácticas organizacionales e individuales, las cuales no tienen una determinación absoluta en el presente, pero que marcan el sentido de las relaciones sociales.

Se podría decir, que la explicación de los procesos sociales deberá superar las visiones desarticuladas y segmentadas de una realidad tota- 
lizada en espacio-tiempo-sociedad, en donde todas las ciencias se encuentren comprometidas. La mayor y más intensa integración mundial contemporánea constituye un reto permanente en la comprensión de los procesos sociales y físicos naturales.

El momento presente que ha integrado desigualmente a las sociedades del mundo, exige tener una visión crítica y una explicación totalizante, como medio para conocer la descomposición, supeditación o liquidación de los proyectos nacionales, así como para su transformación, progreso y desarrollo.

La evidencia de la debilidad de los estados latinoamericanos para regular sus sociedades, la pérdida de capacidad organizativa y de una aspiración de vida y de sociedad de los sectores subordinados, así como la degradación de los procesos democráticos, de representación social de las funciones y órganos públicos y la corrupción de las clases políticas son algunas de las expresiones de la crisis contemporánea de nuestra América Latina.

La democracia, la política pública, la calidad de vida han necesitado de los estados, pero no han sido creaciones estatales, han sido los diversos actores de las sociedades quienes han pautado a los estados y han viabilizado las transformaciones y la vida colectiva. La superación de la crisis del devenir político de los estados es una tarea de las sociedades y no de las clases políticas ni de ningún autócrata iluminado.

La reconstitución social de los estados es una necesidad y aspiración para nuestros pueblos. 